\title{
Cardiovascular and diabetes mortality determined by nutrition during parents' and grandparents' slow growth period
}

\author{
G Kaati $^{1}$, LO Bygren ${ }^{*}$ and S Edvinsson ${ }^{2}$ \\ ${ }^{1}$ Department of Community Medicine and Rehabilitation, Social Medicine, Umea University, Umea, Sweden; \\ ${ }^{2}$ Demographic Database, Umeå University, Umeå, Sweden
}

Overfeeding and overeating in families are traditions that are often transferred from generation to generation. Irrespective of these family traditions, food availability might lead to overfeeding, in its turn leading to metabolic adaptations. Apart from selection, could these adaptations to the social environment have transgenerational effects? This study will attempt to answer the following question: Can overeating during a child's slow growth period (SGP), before their prepubertal peak in growth velocity influence descendants' risk of death from cardiovascular disease and diabetes? Data were collected by following three cohorts born in 1890, 1905 and 1920 in Överkalix parish in northern Sweden up until death or 1995. The parents' or grandparents' access to food during their SGP was determined by referring to historical data on harvests and food prices, records of local community meetings and general historical facts. If food was not readily available during the father's slow growth period, then cardiovascular disease mortality of the proband was low. Diabetes mortality increased if the paternal grandfather was exposed to a surfeit of food during his slow growth period. (Odds Ratio 4.1, 95\% confidence interval $1.33-12.93, P=0.01$ ). Selection bias seemed to be unlikely. A nutrition-linked mechanism through the male line seems to have influenced the risk for cardiovascular and diabetes mellitus mortality.

European Journal of Human Genetics (2002) 10, 682 -688. doi:10.1038/sj.ejhg.5200859

Keywords: childhood overeating; slow growth period; transgenerational effects; cardiovascular disease; diabetes mellitus; mortality

\section{Introduction}

Overeating among children and adolescents may programme their lipid and other metabolic systems for life. ${ }^{1}$ A mother's own nutrition during her childhood may influence her child's risk for cardiovascular disease, diabetes mellitus type II, and hypertension ${ }^{2}$ in adulthood and the effects of her nutrition probably cover a wider range of disease determinants. ${ }^{3}$ The nutrition of the grandmother during her pregnancy influences the mother's nutrition in

\footnotetext{
*Correspondence: LO Bygren, Department of Community Medicine and Rehabilitation, Social Medicine, Umeå University, S-901 85 UMEA, Sweden. Tel: +46 90785 2488; Fax: +46 901379 02;

E-mail: Lars.Olov.Bygren@socmed.umu.se

Received 21 June 2002; revised 14 June 2002; accepted 18 June 2002
}

utero which in turn influences the grandchild's birth weight. $^{4}$

Our interest in the sequels of early life programming and change in the amount of food energy began with Forsdahl's hypothesis that poverty in childhood or adolescence programmes the organism for low energy intake and not for today's high-energy food. The increase in food availability, Forsdahl hypothesised, partly explained some of the incidence of cardiovascular disease. ${ }^{5}$ Barker moved the focus back even further to the early stages of life, which lead to the foetal origin hypothesis. He introduced us to the findings that poor food intake during mid-pregnancy results in an enlarged placenta. ${ }^{6}$ Placenta size brought us to the issue of genomic imprinting. ${ }^{7}$ Hoet $^{8}$ found that dietary protein change during the intrauterine life had delayed 
effects on the offspring's pancreas and insulin secretion. We found that a change in food availability during intrauterine life increased adult 'stroke', sudden death from disease. ${ }^{9}$ Our interest in cardiovascular disease prevention ${ }^{10}$ and the risk factors related to these delayed effects of early natal nutrition took us back still further to the genome. We asked whether variation in childhood nutrition could influence the maturing gametes. We reasoned that exposure to a poor diet during a period of great need for energy at the prepubertal growth velocity peak and exposure to plenty of food during the slow growth period (SGP) compared to intermediate food availability could be expected to result in high cardiovascular mortality in subsequent generations. However, cardiovascular deaths had a dose-response to the food energy availability during ancestors' SGP only. This in turn depended on prolonging of the survival. Hence, for a period of time transgenerational effects on longevity has attracted our interest. ${ }^{11}$ We returned to study cardiovascular causes of death enlarging our body of material by another two cohorts.

Besides genetic selection through differential survival/ fertility, one mechanism for transgenerational effects could be epigenetic inheritance. How genomic imprints are initiated, maintained, or erased influences normal or abnormal development and ultimately long-term prevention of disease. ${ }^{12,13}$ A transgenerational 'feed-forward' control loop has been proposed that links grandparents' nutrition with the grandchild's growth. The mechanism could be a specific response to the grandparents' nutritional state, which directly modifies the setting of the gametic imprint on one or more genes. ${ }^{14}$

The purpose of this study was to consider the possible transgenerational effects on cardiovascular mortality from nutrition during the slow growth period of childhood.

\section{Materials and methods}

The cohorts used for this analysis consisted of 239 probands from three 50\% random samples, which resulted in 320 individuals born 1890, 1905 and 1920 in the parish of Överkalix in northern Sweden. The cohorts were followed in the local parish registers of the Swedish and Finnish communities as they moved about, and most of them could be traced to their death, emigration, or current residence. Three could not be traced at all, and nine emigrated. (Eight of the latter were 15-23 years old, and one was 46 years old at the time of emigration). Causes of death were not specified in 14 cases, and 44 were still living, most of them born in 1920. This left us with 250 probands whose death was specified. For 22 of the older generation, only the birth year was available. These were assigned a mid-year birth date. Of the 250, another 11 probands were excluded from the analysis because a birth year was missing for a parent or grandparent. Hence, the cohorts for analysis included 239 probands and each of their parents and grandparents, which resulted in six individuals per proband (Table 1).

The availability of food in the area during any year was classified based on regional harvest statistics (un-printed), grain prices, ${ }^{15}$ the estimates of a 19 th century statistician, ${ }^{16}$ and general historical facts. Food availability was classified as poor, moderate, or good. Most harvests were completed in September, and the slaughtering of pigs and cattle occurred later in the fall. We used 1 May the year after a crop failure as the time when food was least available. The period following a good harvest when food was most available was represented by 1 November, while intermediate availability was represented by 1 July. The age of a parent or grandparent on those dates was used to determine the availability of food during his or her SGP.

The SGP was determined from the growth velocity during childhood measured in centimetre increases per year. The ages for SGP were set at 8-10 years for girls and 9-12 years for boys. The period had to be estimated from a modern cohort, and it turned out to be shorter for girls than for boys. ${ }^{17}$ Furthermore, the successive decrease in age at puberty during the 19th and 20th centuries had to be taken into account. ${ }^{18}$ The delay of the onset of puberty in parents and grandparents and hence the SGP compared to the modern cohort was set at 1 year.

A multiple logistic model was applied with two causes of death, cardiovascular disease and diabetes mellitus, as outcome variables. The cause of death was taken from the parish registers and coded at Statistics Sweden, according to the ninth international revision of the classification of diseases (ICD-9). A cardiovascular death was defined as caused by hypertension, coronary artery disease, or stroke; that is, at least one ICD-9 number in the class 400-439 coded as direct, intermediate, underlying, or contributory cause of death. A diabetes death was also noted when the ICD-9 number 250 was one of the causes. Age at death was used as a covariate. The access of parents and grandparents to a relative abundance of food were explanatory variables. Three explanatory variables were identified: exposure to a 1 November with a surfeit of food but not a 1 May after a crop failure during the SGP; exposure to 1 May after

Table 1 The samples, the attrition and the cohorts used for the analysis

\begin{tabular}{lcccc}
\hline & \multicolumn{4}{c}{ Birth year } \\
& 1890 & 1905 & 1920 & All \\
\hline Sample & 108 & 99 & 113 & 320 \\
Not traced & 1 & 0 & 2 & 3 \\
Emigrated & 4 & 3 & 2 & 9 \\
Alive at end of follow-up & 0 & 2 & 42 & 44 \\
Cause of death unknown & 10 & 3 & 1 & 14 \\
Year of birth missing & $0^{\mathrm{a}}$ & $4^{\mathrm{a}}$ & $7^{\mathrm{a}}$ & $11^{\mathrm{a}}$ \\
Cohort, probands & 93 & 87 & 59 & 239 \\
'Participation' \% & 86 & 87 & 52 & 75 \\
\hline
\end{tabular}

${ }^{\mathrm{a}}$ Not excluded above. 
a crop failure but not a 1 November with a surfeit of food during the SGP; and exposure to moderate availability throughout the entire SGP.

\section{Statistical analysis}

Bivariate and three multiple logistic regression analyses were performed with cardiovascular and diabetes deaths as the respondent variables. In the first model, the probability of contracting diabetes and cardiovascular disease when parents and grandparents were exposed during their SGP to some year of famine but no year of good harvest were compared with the probability when they were exposed both to years of plenty and scarcity or to years of intermediate harvests. In the second model, the probability for the diseases when an ancestor was exposed to some year of good harvest but to no year of famine were compared with the probability when ancestors were exposed to both famine and a surfeit of food during their SGP or exposed to intermediate years only. In the third analysis, the probability of ancestors being exposed to intermediate availability only during their SGP was compared with the probability when ancestors were exposed to either a surfeit of food or poor availability during their SGP and intermediate years only. Those who had been exposed to both - a year with poor availability and a year with a surfeit of food during their SGP - were treated as 'zero' in the analyses. This group was composed of $7-22 \%$ of ancestors, and it included 27 mothers, 52 fathers, 16 maternal grandmothers, 41 maternal grandfathers, 16 paternal grandmothers, and 29 paternal grandfathers. The explanatory variables were introduced in a logical sequence. After the covariate age at death, the variables for the mother were introduced, followed by the other variables in the following order: father, maternal grandmother, maternal grandfather, paternal grandmother, and paternal grandfather. The program used was PROC LOGISTIC in SAS.

\section{Results}

\section{Exposure}

During the 19th century and the first years of the 20th century the study area was isolated and impoverished and the crops were often meagre. We classified the harvests of the years 1800, 1812, 1821 and 1829 as total crop failures. During the 1831-36 period, all of the years except 1834 suffered a total crop failure; however, because 1834 was affected by lack of seed-corn, we also classified it as a year with total crop failure. This was a decade of hardships. We also classified 1809 as a total crop failure because of hostilities between two armies, which requisitioned much of the local food stock and interfered with the harvest. There were total crop failures in 1851 and 1856, and the harvests in 1867, 1877, 1881, 1888 and 1889 were very poor.

A surfeit of food was available after the harvest in 1799, $1801,1813-15,1822,1825-26,1828,1841,1844,1846$,
$1853,1860-61,1863,1870,1876,1879$ and 1880. All the other years had moderate harvests - neither very poor nor abundant.

\section{Exposure and survival}

The three cohorts each had unique exposure to poor and good availability of food during their SGP. The paternal grandfathers exposure to food availability turned out to be of particular interest. Those of the 1890 birth cohort had the most diverse exposure and those of the 1920 birth cohort few and single years of poor availability (Table 2). A shorter survival of probands when the paternal grandfather had been exposed to plenty of food during SGP was most obvious for the 1905 birth cohort and less obvious for the 1890 birth cohort. In the 1920 birth cohort, this could not be demonstrated (data not shown). The age at death was included as a covariate in the present model.

\section{Number of events caused by cardiovascular disease} There were 123 probands for whom at least one of the causes of death was cardiovascular disease in the range of ICD-9 numbers 400-439. Diabetes mellitus, ICD-9 number 250, was present in 19 deceased.

\section{Cardiovascular death determined by parents' and grandparents' nutrition during their SGP}

When a father, during his SGP, experienced a poor availability of food or famine, his son was protected against cardiovascular death. The Odds Ratio (OR) between probands whose father had this experience and other probands was 0.42 and the $95 \%$ confidence interval $0.18-$ 0.99. There was a slight tendency towards protection from cardiovascular death if the paternal grandmother had the same exposure to a crop failure during her SGP (OR 0.54 c.i, $0.26-1.15 P=0.11)$. On the other hand, the probands

Table 2 The exposure, by number of years during the SGP, to poor and good availability of food for the three birth cohorts' paternal grandfathers

\begin{tabular}{|c|c|c|c|}
\hline \multirow{2}{*}{$\begin{array}{l}\text { Paternal } \\
\text { grandfathers }\end{array}$} & \multicolumn{3}{|c|}{ Birth cohort of probands } \\
\hline & 1890 & 1905 & 1920 \\
\hline \multicolumn{4}{|c|}{ Poor availability } \\
\hline 0 year & 42 & 51 & 59 \\
\hline 1 year & 18 & 18 & 43 \\
\hline 2 years & 14 & 7 & 0 \\
\hline 3 years & 11 & 9 & 0 \\
\hline 4 years & 21 & 9 & 1 \\
\hline$\Sigma, n$ & 106 & 94 & 103 \\
\hline \multicolumn{4}{|c|}{ Good availability } \\
\hline 0 year & 50 & 43 & 37 \\
\hline 1 year & 31 & 28 & 46 \\
\hline 2 years & 20 & 21 & 15 \\
\hline 3 years & 5 & 2 & 5 \\
\hline 4 years & 0 & 0 & 0 \\
\hline$\Sigma, n$ & 106 & 94 & 103 \\
\hline
\end{tabular}


tended to be protected from cardiovascular disease if the mother had been exposed to a surfeit of food during her SGP (OR 0.45, c.i. $0.21-1.01, P=0.05$ ) (Table 3).

\section{Diabetes death determined by parents' and grandparents'} nutrition during SGP

In 19 probands diabetes (ICD-9 no. 250) was the official underlying, intermediate, direct or contributing cause of death. They all had a cardiovascular (ICD-9 no. 400-439) cause of death as well. If the paternal grandfather was exposed to crop failure during his SGP, then the proband had a tendency to be protected from diabetes as the cause of death (OR 0.35 , c.i. $0.11-1.16, P=0.09$ ). If the maternal grandmother had the same exposure, the opposite tendency prevailed (OR 2.73, c.i. 0.96-7.80, $P=0.06$ ), and those grandchildren seemed not to be protected from diabetes.

In the bivariate analysis, there was a tendency of probands to be protected from diabetes when the father lived through a year or years of a surfeit of food during his SGP (OR 0.14, $P=0.06$ ). The same experience for the grandfather tended to be followed by a higher risk for the probands dying from diabetes, according to the bivariate analysis (OR 2.34, $P=0.09$ ). In the multivariable analysis, a father's exposure to a surfeit of food during his SGP tended to protect the proband from diabetes (OR 0.13, c.i. $0.02-$ 1.07, $P=0.06)$. However, if the paternal grandfather was exposed to a surfeit of food during his SGP, then the proband had an over-mortality in diabetes (OR 4.1, c.i. $1.33-12.93, P=0.01)$ when age at death and the effects of possible overeating among parents and grandparents during their respective SGP were taken into account.

\section{Fitness}

Selection might have resulted in a similar average age at death of survivors up to at least 30 years and a diminishing variation around the average over the generations. In the birth cohorts born in 1890 and 1905, where most probands had died, the average age at death and the variation around it were similar across the generations (Table 4).

The response to availability of food during the SGP might reflect earlier selection, for instance, by a high mortality during the first year after birth. The paternal grandfathers exposed to poor availability of food during their infancy had an average life span 69.5 years. Those exposed to good availability of food during this first year of life had an average life span of 69.9 years. Those exposed to intermediate harvests had an average life span of 69.5 years.

Table 3 Probands' probability of cardiovascular (ICD-9 numbers 400-439) death related to their ancestors' exposure to crop failure (and no year of good availability) to a surfeit of food (and no year of poor availability) or to moderate availability of food only during their own slow growth period (SGP) prior to the prepubertal peak. Odds ratio and $95 \%$ confidence interval

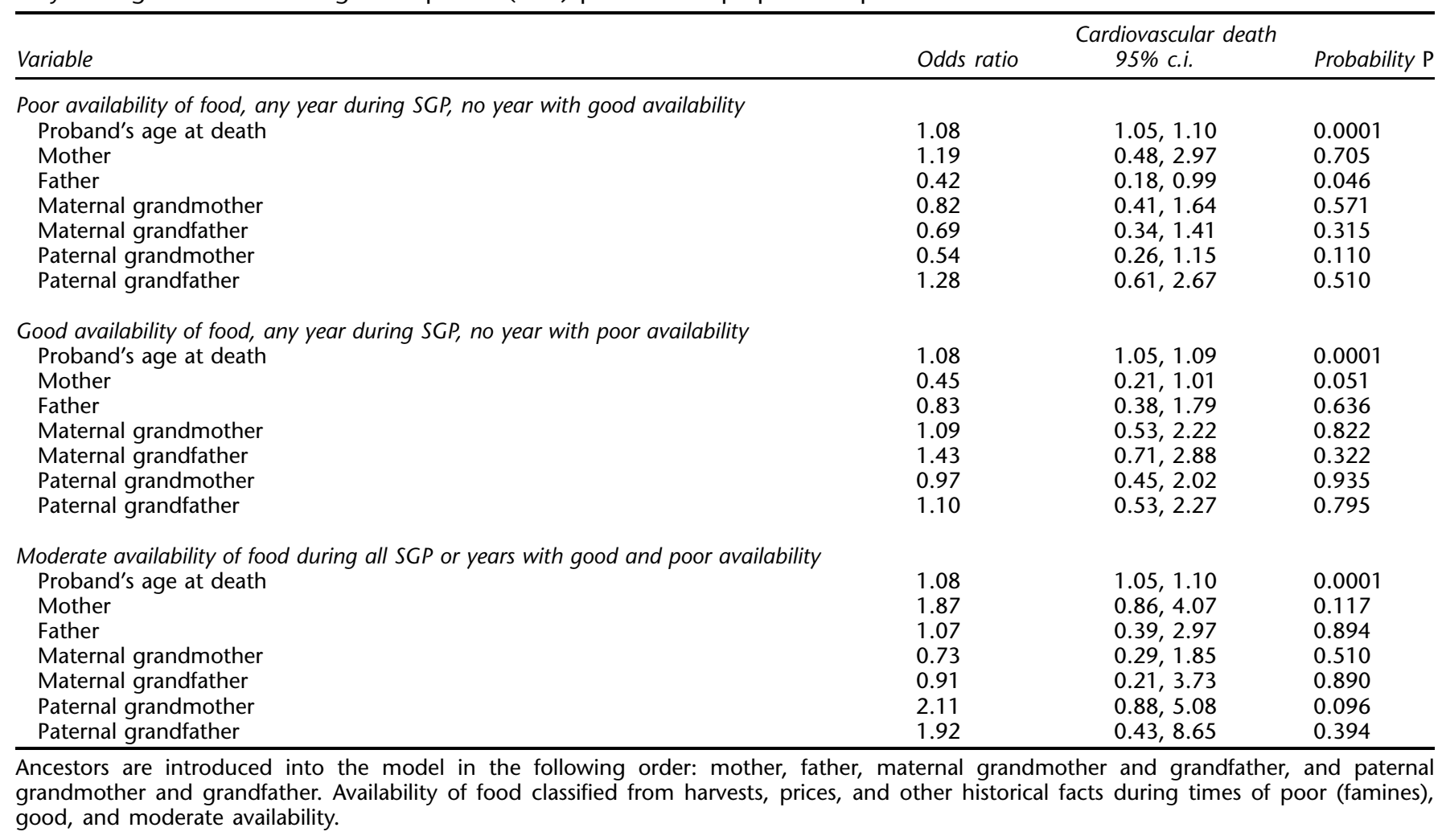


The size of the sibship that included the proband was the dependent variable and the availability of food during the SGP for ancestors was the independent variable in one model. The probands' sibship whose paternal grandfathers had been exposed to a surfeit of food during their SGP numbered 0.66 less than expected and the number of these grandchildren when the paternal grandfather was exposed to a poor availability were 0.61 more than expected according to the model. If the children's father had been exposed to a surfeit during his SGP, the number of children was 0.82 more than expected. (Table 5).

Table 4 The average age at death for survivors up to at least 30 years of age among probands $(n=148)$ and ancestors $(n=1177)$ born 1890 and $1905(n=148)$, and the standard deviation around the average

\begin{tabular}{lllll}
\hline & \multicolumn{2}{c}{ Men } & \multicolumn{3}{c}{ Women } \\
& Age at death & SD & Age at death & SD \\
\hline Probands & 72.5 & 13.2 & 73.8 & 16.2 \\
Parents & 72.5 & 12.1 & 69.2 & 15.3 \\
Maternal grandparents & 68.3 & 13.7 & 69.2 & 15.4 \\
Paternal grandparents & 69.0 & 13.6 & 72.2 & 14.6 \\
\hline
\end{tabular}

The average age of the probands' fathers at the birth of their first child was 27.9 years. Whether the paternal grandfather was exposed to a year of surfeit but no famine during his SGP as opposed to the other way around made no detectable difference $(0.4$ years, $P=0.48)$. If the fathers themselves were exposed in the same way, the difference was 0.5 years $(P=0.53)$.

For the paternal grandfathers we could only calculate the age at birth of the probands' fathers who were rarely firstborn. The average age was 33.6 years. The exposure described above revealed no detectable selection. The difference was 0.6 years, $(P=0.50)$.

\section{Discussion}

We have previously found an association between longevity and food availability during the paternal grandfather's SGP. ${ }^{11}$ In this study we have looked specifically at cardiovascular deaths, including diabetes mellitus.

The number of probands with diabetes on their death certificates was very small and does not really allow for the multivariable control of a large number of possible confounders. However, the bivariate influence of overfeeding during the paternal grandfather's SGP was, in itself, indicative of some effect on the proband.

Table 5 Number of the probands' ( $n=302$ ) sisters and brothers related to their ancestors access to food during their respective slow growth period (SGP) prior to the prepubertal peak

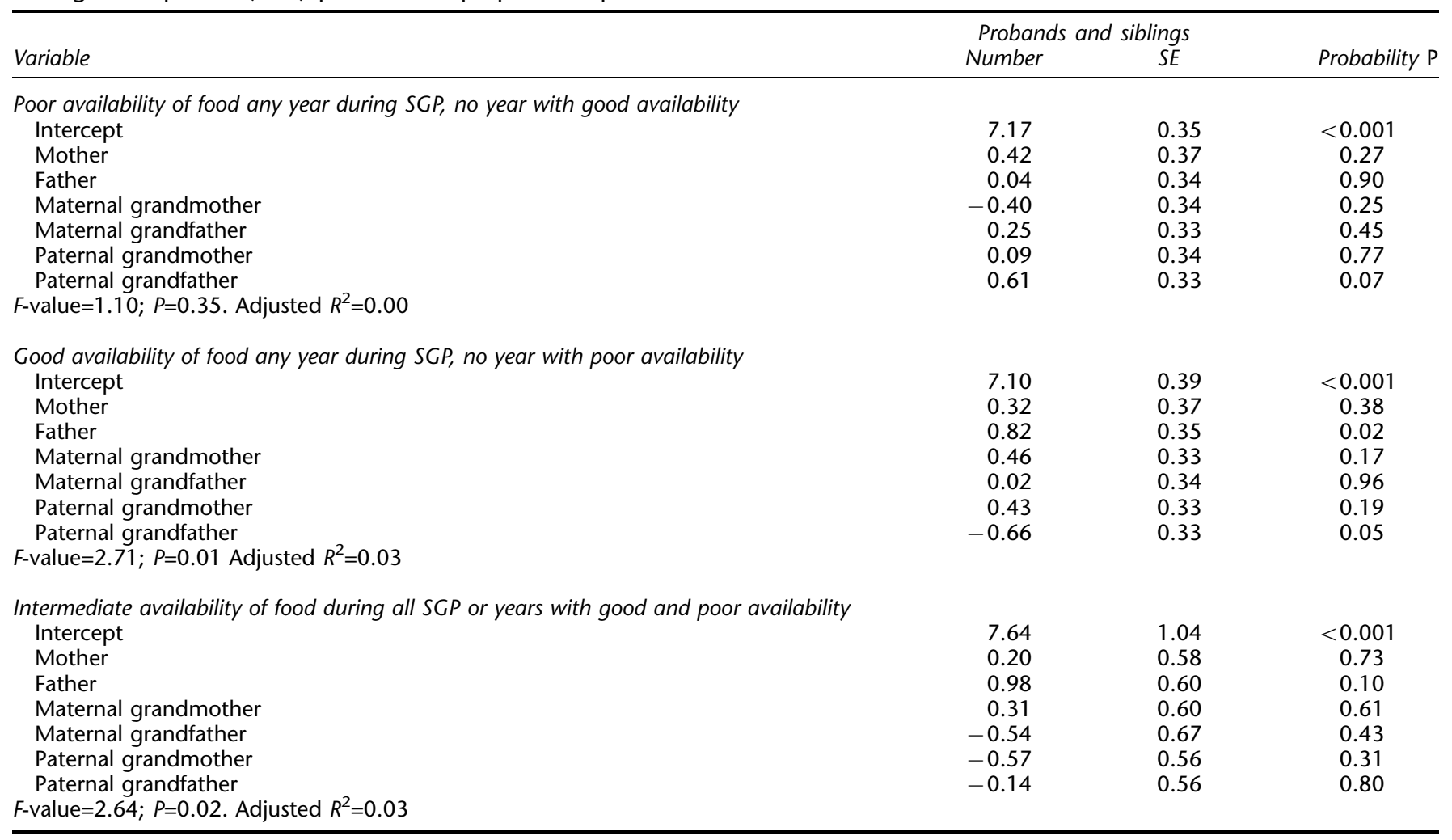


For 22 individuals from the older generations, we found only the year of birth and not the date of birth. A sensitivity analysis excluding them, however, changed results very little (data not shown). In order to establish the period of slow growth velocity, we used a modern cohort and determined the SGP from the growth velocity in $\mathrm{cm} /$ year. We then added 1 year because puberty occurred about 1 year later in the older generations. Furthermore, age at puberty for this older group is known to have had a more skewed distribution to the right than it does today. ${ }^{18}$ However, we did not consider this. Consequently, our delineation of the SGP is approximate, which might mean that some effects of different nutrition could not be detected.

The attrition rate was 25\%, the samples included 320 probands and we followed 239. Another $7-22 \%$ of parents or grandparents had been exposed to both a famine and a year with surfeit of food during their SGP, which could be seen as a type of attrition as well. Hence, we assigned them 'zero' in the analyses. The high attrition rate could have distorted the results. We do not know what the older generations actually received from the available food supplies. The individual's social class coupled with the socio-economic circumstances of the area contributes independently to health outcomes. ${ }^{19}$

Furthermore, the availability of food was determined for the province as a whole, not just for our small research area, but that means that access to relief supplies within $200-300 \mathrm{~km}$ was unlikely. Food relief from farther away was impossible for people living in the 19th century because there were no railways or roads, and in the winter the frozen Baltic Sea prevented any transport over water.

The outcome parameter, that is, cardiovascular and diabetes mortality, was collected from parish registers and was based on death certificates that are known to be less than accurate with respect to cardiovascular causes. The number of probands in each of the three cohorts was small. Diabetes mellitus, for instance, was a cause of death in only 19 cases, and we do not know whether they suffered from type- 1 or type- 2 diabetes. The small sample of probands might have left real effects undiscovered.

The probands' own nutrition during embryonic and foetal life might have had significant bearing on stroke in adulthood. ${ }^{9}$ Childhood experiences, social environment, circumstances of the adult life, ${ }^{19}$ and psychological circumstances might have had a long-term influence on the probands' management of risks for cardiovascular disease. None of these possible effects was taken into account.

\section{Interesting results}

The most intriguing result is that nutrition-related circumstances of the social environment had transgenerational associations with cardiovascular and diabetes-related deaths, and that transmissions were down the male line.

When the father $(P=0.05)$ and perhaps the paternal grandmother $(P=0.11)$ were exposed to a famine during their SGP, the proband was protected against cardiovascular causes of death. Furthermore, if the paternal grandfather lived through a famine during his SGP it tended to protect the proband from diabetes $(P=0.09)$. Most interesting, however, was the finding that if the paternal grandfathers had access to a surfeit of food during their SGP, the probands (their grandchildren) had a fourfold over-risk for death of diabetes mellitus according to the point estimate $(P=0.01)$.

\section{Selection and fitness}

Ancestors of the proband were surviving cohorts and it is possible that genetic selection through differential survival/fertility might explain the findings. The variation around the (similar) average ages at death did not decrease over the three generations, which might mean that selection had not occurred (Table 2). The paternal grandfathers exposed to poor or good availability of food during their infancy were nearly the same average age at death. The paternal grandfather's age when the father of the proband was born was not coherent with the exposure during his SGP. In addition, the father's age at the birth of his firstborn child was not coherent with the exposure during his SGP. If exposure during the SGP had revealed selection based on survival/fertility, then such selection should be detectable in others and not just in the paternal grandfathers. One indication, which is difficult to interpret, was the fact that the number of children in the probands' sibship was higher when the grandfather 'starved' during the SGP and when the father had been exposed to a surfeit of food during his SGP.

\section{Analogies as to mechanisms}

Genomic imprinting in its classical genetic sense is not applicable here as it can only happen at the time of fertilisation. The lack of support for genetic selection as a mechanism raises the question, however, as to whether the nutrition-related transgenerational effect down the male line involves direct epigenetic modification of DNA and/or the associated histones. Epigenetic inheritance has been described in mice $\mathrm{e}^{20,21}$ and in proposing a feed-forward loop linking grandparental nutrition with their grandchildrens growth Pembrey argued that imprinted genes are good candidates for mediating such transgenerational effects. ${ }^{14}$ The question remains if such inheritance will turn out to happen during the SGP.

The over-risk found for death with diabetes directs our speculations to variation at the variable number tandem repeat (VNTR) minisatellite $5^{\prime}$ of the insulin gene which is associated with type-1 diabetes. Variation, most plausible in the VNTR, influences type- 2 diabetes susceptibility. This effect is mediated exclusively by the paternally derived allele, which implicates an imprinted gene (possibly IGF2) in the pathogenesis of type- 2 diabetes. ${ }^{22}$ Ins 2 in mice and IGF2 in the yolk sac are likewise expressed solely from the 
paternal allele hinting at later insulin and growth related diseases. $^{23}$

Nutrition affects ovaries and testes from the moment they form during foetal life through maturity. ${ }^{24}$ Too little is known to speculate on how food availability during the SGP might impact epigenetically on the maturing male germ line, but in mice new parental-specific genomic imprints are introduced when sperm and oocytes begin to mature. $^{25}$

The probands had a tendency to be protected from cardiovascular death if the mother lived through a year or years with a surfeit of food during her SGP $(P=0.05)$. That result points not only to the DNA of the mother's allele but also to the cytoplasm of the ovum and the influence of nutrition on the height of the mother and size of her pelvis, - both of which influence the probands' risk for cardiovascular disease. Therefore, this finding is not easy to interpret. Many other environmental influences might have been at work as nutrition is coherent with other determinants such as infections. ${ }^{26}$

In conclusion, these epidemiological findings draw attention to transgenerational effects down the male line of nutrition-related circumstances during a period of childhood with a bearing on over-risks for cardiovascular disease and diabetes.

\section{Acknowledgements}

We thank Dr Lennart Bäckman, and Lars Age Johansson for their contribution to the study, which was supported by a grant from the Swedish Council for Working Life and Social Research (FAS 20011061).

\section{References}

1 McGill Jr HC: Nutrition in early life and cardiovascular disease. Curr Opin Lipidol 1998; 9: 23-27.

2 Martyn CN, Barker DJ, Osmond C: Mothers' pelvic size, fetal growth, and death from stroke and coronary heart disease in men in the UK. Lancet 1996; 348: 1264-1268.

3 Waterland RA, Garza C: Potential for metabolic imprinting by nutritional perturbation of epigenetic gene regulation; in Black RE and Michaelson KF (eds): Public Health Issues in Infant and Child Nutrition. Nestle Nutrition Workshop Series Vol. 48. Philadelphia: Lippincott Williams \& Wilkins, 2002.

4 Lumey LH, Stein AD: Offspring birth weights after maternal intrauterine undernutrition: a comparison within sibships. Am J Epidemiol 1997; 146: 810-819.

5 Forsdahl A: Are poor living conditions in childhood and adolescence an important risk factor for arteriosclerotic heart disease? Br J Prev Soc Med 1977; 31: 91-95.
6 Barker DJP: Mothers, babies and health in later life. 2nd edn. Edinburgh: Churchill and Livingston, 1998.

7 Hall JG: Genomic imprinting: nature and clinical relevance. Ann Rev Med 1997; 48: 35 - 44.

8 Hoet JJ: Influence of dietary changes in the development of the fetal pancreas-consequences later in life. Isr J Med Sci 1991; 27: $423-424$.

9 Bygren LO, Edvinsson S, Broström G: Change in food availability during pregnancy: Is it related to adult sudden death from cerebro- and cardiovascular disease in offspring. Am J Hum Biol 2000; 12: 447-453.

10 Sjöström M, Karlsson AB, Kaati G, Yngve A, Green LW, Bygren LO: A four week residential program for primary health care patients to control obesity and related heart risk factors: effective application of principles of learning and lifestyle change. Eur J Clin Nutr 1999; 53 (Suppl 2): S72-S77.

11 Bygren LO, Kaati G, Edvinsson S: Longevity determined by ancestors' overnutrition during their slow growth period. Acta Biotheoretica 2001; 49: 53-59.

12 Picton H, Briggs D, Gosden R: The molecular basis of oocyte growth and development. Mol Cell Endocrinol 1998; 145: 27 -37.

13 Kato Y, Rideout 3rd WM, Hilton K, Burton SC, Tsunoda Y, Surani MA: Developmental potential of mouse primordial germ cells. Development 1999; 126: $1823-1832$.

14 Pembrey M: Imprinting and transgenerational modulation of gene expression; human growth as a model. Acta Genet Med Genellol 1996; 45: 111-125.

15 Jörberg L: A history of prices in Sweden 1732-1914. Lund, Sweden: CWK Gleerup, 1972.

16 Hellstenius J: Skördarna i Sverige och deras verkningar. Harvests in Sweden and their repercussions. Stockholm, Sweden: Statistisk Tidskrift, 1871; pp 77-119.

17 Prader A, Largo RH, Molinari L et al: Physical growth of Swiss children from birth to 20 years of age. First Zurich Longitudinal Study of Growth and Development. Helv Paediatr Acta 1988; 43 (Suppl): 52.

18 Tanner JM: A History of the Study of Human Growth. Cambridge: Cambridge University Press, 1981.

19 Smith GD, Hart C, Watt G et al: Individual social class, area-based deprivation, cardiovascular disease risk factors, and mortality: the Renfrew and Paisley Study. J Epidemiol Community Health 1998; 52: $399-405$.

20 Morgan HD, Sutherland HG, Martin DI, Whitelaw E: Epigenetic inheritance at the agouti locus in the mouse. Nature Genetics 1999; 23: 314-318.

21 Wolff GL, Kodell RL, Moore SR, Cooney CA: Maternal epigenetics and methyl supplements affect agouti gene expression in Avy/a mice. FASEB J 1998; 12: 949-957.

22 Huxtable SJ, Saker PJ, Haddad L et al: Analysis of parent-offspring trios provides evidence for linkage and association between the insulin gene and type 2 diabetes mediated exclusively through paternally transmitted class III variable number tandem repeat alleles. Diabetes 2000; 49: 126-130.

23 Moore GE, Abu-Amero SN, Bell G et al: Evidence that insulin is imprinted in the human yolk sac. Diabetes 2001; 50: 199-203.

24 Gosden R, Krapez J, Briggs D: Growth and development of the mammalian oocyte. Bioessays 1997; 19: $875-882$.

25 Surani MA: Immaculate misconception. Nature 2002; 416: 491 493.

26 Jackson AA: Nutrients, growth, and the development of programmed metabolic functioning. Short and Longterm Effects of Breast Feeding in Child Health 2000; 478: 41-55. 